e-ISSN: 2721-9038

p-ISSN: 2721-902X

\title{
PENGGUNAAN METODE PEMBELAJARAN YANG TEPAT DALAM MEMAHAMI KARAKTER SISWA SEBAGAI UPAYA PENERAPAN KURIKULUM 2013
}

\author{
Julina Wati $^{{ }^{*}}$, Fiza Radasari ${ }^{2}$, Musnaini $^{3}$, dan Hasby ${ }^{4}$ \\ ${ }^{1,2,3,4}$ Program Studi Pendidikan Kimia, FKIP Universitas Samudra \\ Jln. Kampus Meurandeh, Langsa 24416 \\ *Email: fizaradasari07@gmail.com
}

\begin{abstract}
Abstrak
Tujuan penelitian ini untuk mendeskripsikan bagaimanakah metode pembelajaran yang tepat dalam memahami karakter siswa sebagai upaya penerapan Kurikulum 2013 pada pembelajaran Kimia materi hidrokarbon dan minyak bumi kelas XI di SMA Negeri 5 Langsa. Penelitian ini dilakukan secara kualitatif melalui tahapan wawancara dan observasi. Sampel yang diambil adalah siswa kelas XI MIPA 1 yang berjumlah 29 orang dan XI MIPA 2 yang berjumlah 30 orang. Dari hasil observasi, penggunaan model Make a Match diaplikasikan pada siswa kelas XI MIPA 1 yang memiliki karakter kurang baik dan model Think Pair Share (TPS) diaplikasikan pada siswa kelas XI MIPA 2 yang berkarakter baik. Model-model ini sangat aplikatif untuk diterapkan pada kedua kelas yang memiliki karakter siswa yang berbeda, dengan meningkatkan hasil sikap dan belajar siswa dalam mempelajari kimia. Dari hasil penelitian, dapat disimpulkan bahwa penggunaan model pembelajaran Make a Match dan Think Pair Share (TPS) yang berbasis metode pembelajaran diskusi berpasangan adalah tepat untuk diterapkapkan dengan baik dalam memahami karakter siswa sebagai upaya penerapan Kurikulum 2013.
\end{abstract}

Kata Kunci: Metode pembelajaran, Model Make a Match, Model Think Pair Share, karakter siswa.

\begin{abstract}
The purpose of this study is to describe how the right learning method in understanding the character of students as an effort to implement the 2013 Curriculum on the learning of hydrocarbon and petroleum chemistry in class XI in Langsa 5 High School. This research was conducted qualitatively through the stages of interview and observation. The samples taken were students of class XI MIPA 1, amounting to 29 people and XI MIPA 2 which amounted to 30 people. From the results of observations, the use of the Make a Match model was applied to students of class XI MIPA 1 who had poor character and Think Pair Share (TPS) models were applied to class XI MIPA 2 students who had good character. These models are very applicable to be applied to both classes that have different student characteristics, by improving student attitudes and learning outcomes in studying chemistry. From the results of the study, it can be concluded that the use of the Make a Match learning model and Think Pair Share (TPS) based on the method of learning in pairs discussion is appropriate to be well applied in understanding the character of students as an effort to implement the 2013 curriculum.
\end{abstract}

Keywords: Learning method, Make a Match model, Think Pair Share model, student character.

KATALIS Jurnal Penelitian Kimia dan Pendidikan Kimia

Vol. 4, No. 2, Desember 2021

Page 32 


\section{PENDAHULUAN}

Setiap individu pada dasarnya ingin menjadi manusia yang ideal, yakni beriman kepada Tuhan Yang Maha Esa, bermoral, cerdas dan bertanggungjawab. Namun kini yang banyak terjadi sebaliknya. Dari berbagai media masa maraknya tindakan yang menyimpang, seperti tindakan yang anarkis,timbulnya konflik sosial, penggunaan bahasa yang tidak santun, seks bebas, serta penyalahgunaan narkoba dan korupsi pada semua kalangan. Hal ini menunjukkan bahwa bangsa Indonesia mengalami krisis moral yang patut diperhatikan.

Berdasarkan hal tersebut, maka pemerintah mengambil tindakan sebagai upaya dalam membangun karakter bangsa Indonesia. Salah satu ruang lingkup yang menjadi sasaran pemerintah dalam membangun karakter tersebut adalah melalui lingkup satuan pendidikan. Pendidikan merupakan tolak ukur suatu bangsa untuk mengetahui kualitas negaranya. Kualitas pendidikan ini tentu bukanlah capaian yang mudah, bergantung pada proses pembelajaran dalam sistem pendidikan tersebut (Sunaengsih, 2016). Satuan pendidikan merupakan suatu wadah yang di dalamnya terkandung sistem dalam membina dan mengembangkan karakter siswa sebagai penerus bangsa. Upaya pembinaan dan pengembangan karakter ini dilakukan dengan empat tahap, yaitu: (a) Pendekatan yang berintegrasi untuk semua mata pelajaran, (b) Pengembangan budaya dalam satuan pendidikan, (c) Pelaksanaan kegiatan kokurikuler dan ekstrakurikuler, serta (d) Pembiasaan perilaku di lingkungan satuan pendidikan. Upaya membangun karakter melalui satuan pendidikan ini dilakukan mulai dari pendidikan usia dini hingga pendidikan tinggi (Kemendiknas, 2010).

Tujuan pendidikan dalam mencerdaskan generasi bangsa dapat dilihat dari capaian siswa baik dari segi pengetahuan (kognitif), sikap (afektif) , dan keterampilannya (psikomotorik). Pencapaian ini tentu dapat diperoleh melalui efektifnya proses pembelajaran (Jannah, 2017). Belajar adalah suatu rangkaian proses dalam memperoleh informasi untuk mempelajari suatu hal agar mencapai tujuan yang diinginkan, sehingga terjadi perubahan dalam berpikir dan berperilaku. Belajar merupakan kegiatan yang fleksibel dilakukan, asalkan waktu dan tempatnya kondusif untuk dilakukannya pembelajaran. Namun, secara formal kegiatan belajar tetap dilakukan di sekolah (Afandi, 2015).

Sekolah merupakan lembaga formal yang mengupayakan tercapinya tujuan pendidikan nasional. Berdasarkan Undang-undang Sistem Pendidikan Nasional No. 20 Tahun 2003 bahwa "tujuan pendidikan nasional yaitu mengembangkan siswa melalui potensi yang dimilikinya agar menjadi manusia yang beriman dan bertakwa kepada Tuhan Yang Maha Esa, berakhlak mulia, sehat, berilmu, cakap, kreatif, mandiri dan menjadi warga negara yang demokratis serta bertanggungjawab" (Depdiknas, 2003). Keberhasilan ini sangatlah bergantung pada kompetensi guru dalam mengolah pembelajaran yang menarik sehingga menciptakan kondisi yang memungkinkan siswa untuk belajar demi tercapainya standar kompetensi. Salah satu upaya yang dilakukan guru untuk menumbuhkan karakter siswa 
e-ISSN: 2721-9038

p-ISSN: 2721-902X

adalah menggunakan metode pembelajaran sebagai bentuk penerapan terhadap kurikulum pendidikan. Kurikulum pendidikan yang digunakan saat ini adalah Kurikulum 2013 yang pendekatan pembelajarannya berorientasi atau berpusat pada siswa (student centered approach).

Kurikulum 2013 merupakan kurikulum yang mengartikan Standar Kompetensi Lulusan (SKL) sebagai kriteria dalam kualifikasi kemampuan lulusan yang melingkupi tiga ranah, yaitu pengetahuan (kognitif), sikap (afektif), dan keterampilan (psikomotorik). Pada kurikulum ini, proses pembelajaran yang dilakukan lebih konkrit, dilengkapi dengan aktivitas mengamati, menanya, mengolah, menyajikan, dan menyimpulkan. Seluruh aktivitas ini bisa dilakukan di sekolah maupun di luar sekolah (masyarakat). Dengan demikian, guru perlu bertindak sebagai fasilitator sekaligus motivator bagi siswa selama pembelajaran, dan bukan menjadi sumber belajar satu-satunya.

Salah satu faktor terpenting di sekolah dalam mengembangkan karakter siswa adalah guru. Dalam UU No. 14 Tahun 2005 tentang Guru dan Dosen, menyatakan bahwa seorang guru harus memiliki empat kompetensi, yaitu kompetensi profesional, pedagogik, kepribadian, dan sosial. Melalui kompetensi-kompetensi tersebut, seorang guru diharapkan mampu mengembangkan nilai-nilai karakter bangsa baik nilai religius, kejujuran, disiplin, serta sikap kepedulian siswa terhadap lingkungan (Adawiah, 2016). Namun sebaliknya. Masih banyak siswa yang berperilaku tidak disiplin, suka berkelahi, tidak hormat terhadap orang tua dan guru,mencontek, bullying verbal/fisik oleh teman sebaya, serta membolos saat pembelajaran berlangsung. Tentu saja, hal ini merupakan tugas dan amanah besar bagi guru untuk mengupayakan pembentukan karakter ini di sekolah. Artinya, guru memiliki peran penting dalam menjadi pendidik, pendorong, pembimbing, fasilitator dan penyokong siswa agar senantiasa berakhlak mulia dalam menuntut ilmu.

Berdasarkan hasil observasi selama magang, kami menemukan kurangnya moral siswa dan motivasi belajarnya terhadap mata pelajaran Kimia, khususnya materi Hidrokarbon dan Minyak Bumi di kelas XI SMA Negeri 5 Langsa. Penyebabnya didasari oleh pemikiran (mindset) siswa terhadap ilmu kimia yang cenderung menganggap kimia itu sulit untuk dipahami karena bersifat abstrak, sehingga siswa cenderung bosan dan malas untuk mempelajari kimia dan mendengarkan guru saat belajar. Hal ini tentu berdampak pada hasil belajarnya. Dengan demikian, perlu adanya metode pembelajaran dengan model pembelajaran yang tepat dalam memahami karakter siswa dan menarik minatnya untuk belajar kimia di dalam kelas.

Berdasarkan permasalahan tersebut di atas, maka perlu dilakukan penelitian untuk mendeskripsikan metode pembelajaran yang tepat dalam memahami karakter siswa sebagai upaya penerapan Kurikulum 2013 pada pembelajaran Kimia kelas XI di SMA Negeri 5 Langsa. 


\section{METODOLOGI PENELITIAN}

Penelitian ini merupakan jenis penelitian kualitatif, yang pengumpulan datanya berupa kata, gambar, dan bukan angka yang berdasarkan hasil pengamatan penggunaan metode pembelajaran berbasis diskusi dengan model Think Pair Share (TPS) dan Make a Match pada mata pelajaran Kimia di kelas XI SMA Negeri 5 Langsa. Sampel dalam penelitian ini adalah para siswa kelas XI MIPA 1 yang berjumlah 29 orang dan XI MIPA 2 yang berjumlah 30 orang.

Menurut Moleong (2014), penelitian kualitatif (qualitative research) adalah merupakan penelitian untuk mendeskripsikan dan menganalisis fenomena, peristiwa, serta aktivitas sosial secara alamiah. Metodologi kualitatif sebagai prosedur penelitian yang menghasilkan data deskriptif berupa kata-kata, baik lisan maupun tertulis dari sampel penelitian yang dapat diamati. Jenis datanya berupa transkrip wawancara (interview).

Model pembelajaran Think Pair Share (TPS) adalah model pembelajaran yang menggunakan metode diskusi secara berpasangan dan dilanjutkan dengan diskusi pleno. Model pembelajaran TPS diawali dengan guru yang memberikan pertanyaan terkait pelajaran untuk dipikirkan (thinking) jawabannya oleh siswa. Selanjutnya guru meminta siswa untuk berpasangan (pairing) dan berbagi (sharing) hasil diskusi berpasangan dibicarakan dalam kelompok (Miftahul, 2011).
e-ISSN: 2721-9038

p-ISSN: 2721-902X

Model pembelajaran Make a Match merupakan suatu model yang dikembangkan oleh Loma Curran pada tahun 1994 (Miftahul, 2011), yaitu siswa diminta untuk mencari pasangan kartu yang merupakan jawaban/soal dan mencocokkannya selama batas waktu tertentu. Bagi yang berhasil akan diberi poin. Salah satu keunggulan dari Make a Match yaitu siswa mencari pasangan sambil belajar menciptakan suasana yang menyenangkan dalam memahami konsep pelajaran.

Teknik pengumpulan data dalam penelitian ini dilakukan melalui wawancara (interview), observasi, dan dokumentasi. Teknik analisis data yang digunakan dalam penelitian ini adalah analisis model interaktif (Interactive Model of Analysis) terhadap guru dan siswa pada mata pelajaran kimia materi Hidrokarbon dan Minyak Bumi di kelas XI. Menurut Miftahul Huda (2011), umumnya wawancara (interview) dalam penelitian kualitatif bersifat open-ended dan mendalam. Dilakukan secara tidak formal demi menggali pandangan subjek yang diteliti tentang banyak hal yang sangat bermanfaat sebagai dasar bagi penelitian lebih jauh. Wawancara dapat dilakukan secara terstruktur maupun tidak terstruktur serta langsung maupun tidak langsung. Namun dalam penelitian ini, wawancara yang dilakukan adalah secara langsung dan terstruktur kepada Guru Pembimbing Magang (GPM) mata pelajaran Kimia dan beberapa siswa kelas XI yang menjadi objek pengamatan saat menjalani program kegiatan magang II di SMA Negeri 5 Langsa dari tanggal 1 sampai 6 Oktober 2018. 


\section{HASIL DAN PEMBAHASAN}

Kegiatan penelitian ini bersifat kualitatif melalui dua tahap, yaitu wawancara (interview) dan observasi. Tahap wawancara (interview) dilakukan terhadap guru mata pelajaran kimia dan beberapa siswa kelas XI yang berbeda, yakni kelas XI MIPA 1 dan XI MIPA 2 di SMA Negeri 5 Langsa. Pada tahap wawancara (interview) terhadap guru, ditemukan fakta bahwa penerapan Kurikulum 2013 menuntut siswa untuk lebih aktif dalam proses pembelajaran, karena sifat pembelajaran yang berpusat pada siswa, sehingga metode diskusi sangat tepat digunakan saat proses pembelajaran berlangsung. Namun faktanya, diantara kelas XI MIPA 1 dan XI MIPA 2 kecenderungan siswa untuk lebih aktif dalam belajar adalah siswa kelas XI MIPA 2 daripada siswa kelas XI MIPA 1. Hal ini dikarenakan adanya perbedaan karakter siswa diantara kelas tersebut, sehingga menuntut guru untuk bisa menemukan metode dan model pembelajaran yang tepat agar siswa lebih mudah dalam memahami materi pelajaran dan proses pembelajaran pun dapat lebih aktif. Pada tahap wawancara (interview) terhadap siswa kelas XI MIPA 1 dan MIPA 2, ditemukan fakta bahwa siswa cenderung sulit memahami materi hidrokarbon dan minyak bumi yang diajarkan guru. Hal ini disebabkan kedua materi tersebut menuntut siswa untuk lebih banyak menghafal teori dan kecenderungan ilmu kimia yang bersifat abstrak.

Dari hasil observasi atau pengamatan pembelajaran di dalam kelas, terdapat persamaan penggunaan
e-ISSN: 2721-9038

p-ISSN: 2721-902X

metode pembelajaran pada kedua kelas, namun dikemas dengan model pembelajaran yang berbeda untuk materi pelajaran yang sama. Pada kelas XI MIPA 1, digunakan model pembelajaran Make a Match dan kelas XI MIPA 2 digunakan model pembelajaran Think Pair Share (TPS). Dari perlakuan pada model pembelajaran Make a Match pada kelas XI MIPA 1, siswa diminta membentuk lima kelompok dan masing-masing kelompok terdiri dari 5 atau 6 orang. Selanjutnya, siswa dibagikan kartu oleh guru sebanyak 12 kartu untuk tiap kelompok yang terdiri dari 6 kartu soal dan 6 kartu jawaban yang berbedabeda. Tiap siswa diberi batasan waktu untuk mencari pasangan jawabannya. Tiap siswa yang berhasil mencocokkan jawaban kartu sebelum waktu habis, maka akan memperoleh tambahan poin.

Beberapa keuntungan dalam penerapan model pembelajaran Make a Match antara lain: (1) Terciptanya suasana yang menyenangkan selama proses pembelajaran ; (2) Kerjasama antar siswa terwujud secara dinamis; (3) Munculnya dinamika gotong royong yang merata pada seluruh siswa; (4) Siswa mencari pasangansambil belajar menciptakan suasana yang menyenangkan dalam memahami konsep pelajaran (Fakhrudin, 2014). Model ini menggunakan metode pembelajaran berbasis diskusi berpasangan yang menyenangkan, sehingga cocok sekali untuk diaplikasikan pada kelas yang karakter siswanya bisa dikategorikan nakal. Nakal dalam arti, sering bolos saat pelajaran dan cenderung enggan mendengar guru saat menerangkan 
pelajaran. Kenakalan ini dapat diatasi saat guru menggunakan metode dan model pembelajaran seperti Make a Match. Namun, tentu saja model ini tidak bisa diterapkan untuk semua materi pelajaran kimia. Hanya saja untuk beberapa materi (teori) yang abstrak dan membutuhkan pemahaman yang lebih bagi siswa.

Dari perlakuan pada model pembelajaran Think Pair Share (TPS) pada kelas XI MIPA 2, siswa dibentuk menjadi lima kelompok dan masingmasing kelompok terdiri dari 6 orang. Model ini menggunakan metode diskusi berpasangan dan dilanjutkan dengan diskusi pleno (Miftahul, 2011). Keuntungan model pembelajaran Think Pair Share (TPS) antara lain menimbulkan rasa tanggungjawab siswa, karena guru memberikan tugas yang harus diselesaikan siswa secara individu terlebih dahulu dan dilanjutkan dengan berpasangan. Melalui proses belajar yang mandiri dan kelompok, siswa menemukan solusi/jawaban dan terlibat langsung selama proses pembelajaran, sehingga motivasi belajar dan hasil belajarnya meningkat dalam pelajaran tersebut. Model ini cocok sekali diaplikasikan untuk kelas yang karakter siswanya aktif dan lebih mudah diatur saat pembelajaran. Karena nakal atau tidaknya siswa dalam belajar, merupakan tanggungjawab besar dan penting bagi seorang guru untuk mencarikan solusi terbaik agar ilmu yang disampaikan kepada siswanya dapat diterima dan dipahami dengan baik, agar tujuan pendidikan nasional dapat tercapai.

\section{KESIMPULAN}

e-ISSN: 2721-9038

p-ISSN: 2721-902X

Berdasarkan hasil yang diperoleh dalam penelitian, dapat disimpulkan bahwa penggunaan model pembelajaran Make a Match dan Think Pair Share (TPS) yang berbasis metode pembelajaran diskusi berpasangan adalah tepat untuk diterapkapkan dengan baik dalam memahami karakter siswa sebagai upaya penerapan Kurikulum 2013.

\section{UCAPAN TERIMA KASIH}

Peneliti mengucapkan terima kasih kepada Kepala SMA Negeri 5 Langsa yang telah memberikan izin kepada peneliti untuk melakukan penelitian di sekolah dan kepada Ibu Nur Maida Sari, S.Pd selaku guru mata pelajaran Kimia di SMA Negeri 5 Langsa yang telah mengizinkan peneliti untuk mengobservasi dan melakukan penelitian saat pembelajaran, serta kepada seluruh siswa kelas XI MIPA 1 dan XI MIPA 2 yang telah terlibat di dalamnya.

\section{DAFTAR PUSTAKA}

Adawiah, R. 2016. Profeseonalitas Guru dan Pendidikan Karakter (Kajian Emperis di SDN Kabupaten Balangan. Jurnal Pendidikan Kewarganegaraan. 6 (11): 939-946.

Afandi, R. 2015. Pengembangan Media Pembelajaran Permainan Ular Tangga untuk Meningkatkan Motivasi Belajar Siswa dan Hasil Belajar IPS di Sekolah Dasar. JINoP (Jurnal Inovasi Pembelajaran). 1 (1): 77-89. 
Depdiknas. 2003. Undang-undang Sistem Pendidikan Nasional No. 20 Tahun 2003. Jakarta: Depdiknas.

Fakhrudin. 2014. Problem Based Learning Approach Through Cooperative Learning Strategy Type Make a Match Against Mathematical Raesoning Ability anf Soft-skill Students, ICMSE 2014, M-170.

Jannah, M. 2017. Pengaruh Penggunaan Media Ular Tangga pada Materi Hidrokarbon terhadap Hasil Belajar Siswa SMAN 1 Kreung Sabee. Prosiding Seminar Nasional MIPA III, Langsa: 30 Oktober 2017. Hal: 141-146.

Kemendiknas. 2010. Buku Induk Pembangunan Karakter. Jakarta: Depdiknas.

Miftahul, Huda. 2011. Cooperatif Learning: Metode, Teknik, Struktur dan Penerapan. Jakarta: Pustaka Belajar.

Moleong, L. J. 2014. Metodologi Penelitian Kualitatif. Bandung: PT. Remaja Rosdakarya.

Sudrajat, Akhmat. 2008. Pengertian Pendekatan, Strategi, Metode, Tekhnik, Taktik dan Model. Jakarta: Bumi Aksara.

Sunaengsih, C. 2016. Pengaruh Media Pembelajaran terhadap Mutu Pembelajaran pada Sekolah Dasar Terakreditasi A. Mimbar Sekolah Dasar. 3 (2): 183-190. 